\title{
The Effects of User and Social Characteristics on Continuous Use Intention among Corporate Mobile SNS Users - With a Focus on Extended Technological Acceptance Model
}

\author{
Joon-Hee Kim ${ }^{1}$, Myeong-Suk Kim ${ }^{2}$, Ryung-Kee Hong ${ }^{3}$ and Jong-Wook Ko ${ }^{4 *}$ \\ ${ }^{1}$ Adjunct Professor, Hoseo Univ., 212-1103, 346-2, Sangdo-ro, Dongjak-gu, Seoul, \\ Republic of Korea \\ ${ }^{2}$ Audit, Joystone Co., 15 Mapodae-ro, Mapo-gu, Seoul, Republic of Korea \\ ${ }^{3}$ Director, Aju Pharm, 71-2 Jinheung-ro, Unpyung-gu, Seoul, Republic of Korea \\ ${ }^{4 *}$ Professor, Dept. Public Administration, Anyang Univ., 37-22 Samdek-ro, \\ Manan-gu, Anyang, Gyeonggi-do, Korea \\ 1perideau@naver.com,2jarakim65@naver.com, ${ }^{3}$ rkhong@ajupharm.co.kr, \\ 4*jwko@anyang.ac.kr
}

\begin{abstract}
The purpose of this study was to investigate the effects of user and social characteristics on continuous use intention among corporate mobile SNS users. Based on the extended technology acceptance model, this study examined user characteristics (personal innovativeness, personal familiarity) and social characteristics (social effects, social interaction) as independent variables of continuous use intention and perceived easiness and perceived usefulness as mediating variables. The data of this study were collected from 332 corporate mobile SNS users with structured questionnaires and analyzed using the SEM technique. This study found that four user and social characteristics variables have positive effects on the two mediating variables and that the two mediating variables positively impacted continuous use intention. Theoretical implications of the findings were discussed and the policy proposals were suggested.
\end{abstract}

Keywords: Corporate mobile SNS, User characteristics, Social characteristics, Continuous use intention

\section{Study objectives and contents}

The media environment to come up as a great power in the information age is a technical media environment necessary for communication between organizations and individuals, organizations and organizations as well as individuals and individuals. In this environment, Social Network Service (SNS), a representative channel of communication, is expanding from the center of the media environment. However, the enterprise SNS in the mobile environment is in the situation of not being able to quickly respond to the recent changes because it is providing one-sided information provision or program rather than promoting users' communication and active participation. In this study, we investigate the effects of personal and social characteristics of corporate SNS users to continuous usage intention in the mobile

Article history:

Received (August 11, 2019), Review Result (September 17, 2019), Accepted (November 5, 2019) 
environment based on the technology acceptance model, and also show the practical implications that can be applied to the effective use by the company and marketing strategy.

The technology acceptance model is the model to be developed to explain and predict user behavior for users who use various information technologies[1], and Davis [2] suggested the technology acceptance model [3], which embodies the determinants of attitude toward behavior of as a concept of perceived availability and perceived ease of use to explain the determinants of information technology acceptance and to present the theoretical justification [2]. Davis, Bagozzi and Warshaw [1] proposed a technology acceptance model 2 that perceived availability and perceived ease of use directly affect behavioral intentions, excluding attitudinal variables in the existing model, and Venkatesh and Bala [4] also modified the existing technology acceptance model and suggested a technology acceptance model 3 that external variables such as individual differences, system attributes, social influence, and facilitating conditions influence the behavior intention and use behavior through perceived availability and perceived ease of use.

Various theoretical models, which elaborate the technology acceptance model, have been presented since the late 1990s [5], Choi [3], and this study is to explore the determinants of continuous use intention of enterprise mobile SNS users based on diverse extended technology acceptance model. In this regard, we examine user characteristics and social characteristics factors as external variables and set two variables, perceived ease of use and perceived availability as intervening variables [1]; Venkatesh and Bala [4].

It was found from related theories and empirical studies Agarwal and Karahanna [6] and Kishore, Patnaik, Mani, and Agrawal [7] found that personal innovativeness and familiarity as user characteristics variable have a positive influence on continuous use intention through perceived ease of use and perceived availability as intervening variables. In addition, Verkasalo, Lopez-Nicolas, Molina-Castillo, and Bouwman [8] and Davis [5] found, social influence and social interaction variables as social characteristics variables have a positive influence on continuous use intention through perceived ease of use and perceived availability as intervening variables.

With regards to the relationship between perceived ease of use and perceived availability as intervening variables, Kishore, Patnaik, Mani and Agrawal [7] and Verkasalo, Lopez-Nicolas, Molina-Castillo, and Bouwman [8] found the perceived ease of use has a positive influence on perceived availability in the study for mobile acceptance intention. In addition, Kim [9] and $\mathrm{Kim}, \mathrm{Ha}$ [10] found that the perceived ease of use influences on perceived availability in the study for continuous use intention of corporate mobile SNS.

In light of the theoretical and empirical studies discussed above, it is expected that user characteristics variable (personal innovativeness, personal familiarity) and social characteristics variable (social influence, social interaction) are positively related to perceived ease of use and perceived availability as intervening variables, which have a positive influence on continuous use intention as a dependent variable. With regards to the relationship between perceived ease of use and perceived availability as intervening variables, perceived ease of use is expected to have a positive effect on perceived availability. The study model based on the above discussions is shown in [Figure 1]. 


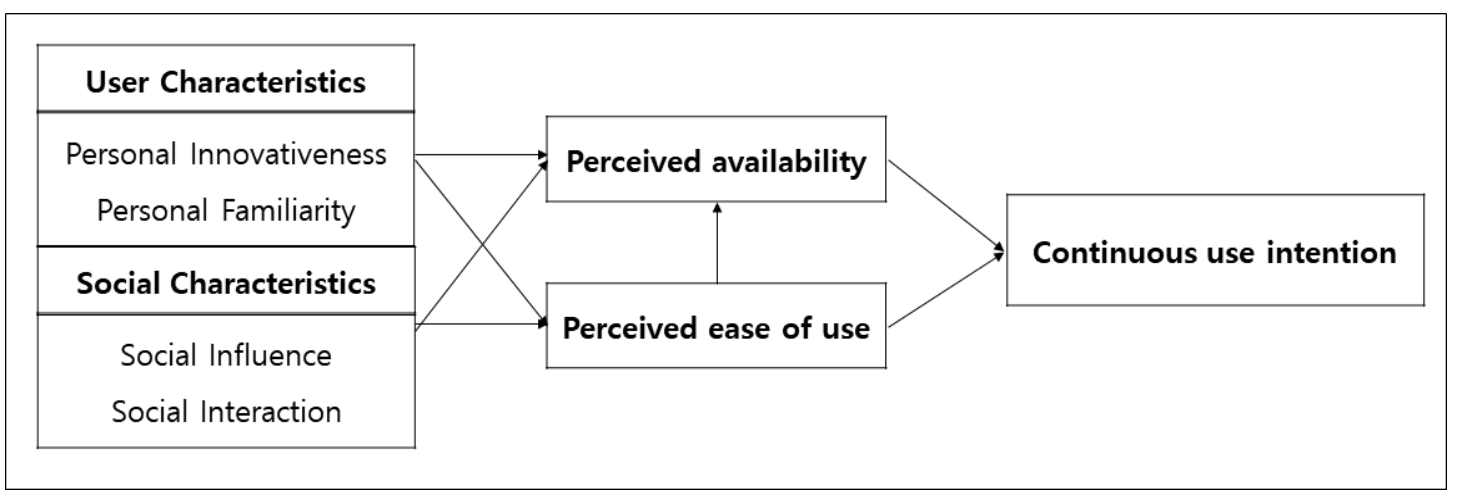

Figure 1. Study model

\section{Study Method}

\subsection{Data collection}

The data for this study were collected from 332 workers in 9 companies, who had experience in using enterprise mobile SNS. Structured questionnaires were used as data collection tools and the collected data were analyzed with structural equation modeling techniques and 332 copies of the 400 copies of the questionnaire, excluding 68 copies, were used for data analysis.

\subsection{Measuring variables}

Personal innovativeness and personal familiarity among user characteristics variables used in this study were measured by selecting 4 5 items from the scales developed by Agarwal and Karahanna [6] and Buellingen and Woerter [11]. Social influence and social interaction among social characteristics variables were measured by selecting 4 questionnaires from the scales developed by Rogers [12], and Venkatesh, Morris, and Davis and Davis [13]. The perceived ease of use as an intervening variable was measured by selecting 5 questionnaires from the scale developed by Davis [2], and perceived availability by selecting 5 questionnaires from the scale developed by Venkatesh, Morris, Davis, and Davis [13]. In addition, continuous use intention as a dependent variable was measured by selecting 4 questionnaires developed by Thong, Hong, and Tam [14]

\section{Analysis result}

\subsection{Analysis results for validity and reliability}

Confirmatory factor analysis by AMOS 22.0 was performed to determine whether the scales used to measure variables have appropriate validity. As a result, the model fit index of the measurement model is .935 , TLI is .924 , CFI is .934 by showing over .90 , and the RMR is .030 , which is smaller than .05 ., showing the model fit was found to be excellent. In addition, the factor loadings for each question were all at least as high as .70 or more, showing to be appropriately loaded, and all AVE and CR values were both higher than .60 and higher than .70 for each. Thus, it is shown that the scales used to measure variables have appropriate convergence and discriminant validity.

On the other hand, Cronbach's alpha of the scale was found to be .859 for individual innovativeness, .832 for individual familiarity, .817 for social influence, .840 for social 
interaction, .838 for perceived ease of use, .805 , and .842 for the continuous use intention, with all exceeding .80. Therefore, the scale used in this study has generally a very satisfactory level of reliability.

\subsection{Study model analysis result}

The research model proposed in this study has applied the analysis technique for structural equation modeling and the analysis results are shown in [Table 1]. The path coefficients shown in Table 1 are all the values with correction of measurement error. In Table 1, it is shown that personal innovativeness $(\beta=.249, \mathrm{P}<.01)$ and personal familiarity $(\beta=.330, \mathrm{P}<.01)$, as user characteristics variables and social influence $(\beta=.137, \mathrm{P}<.05)$ and social interaction $(\beta=.197$, $\mathrm{P}<.01)$ as social characteristics variables all have a significant positive effect on perceived ease of use. Moreover, it is shown that personal innovativeness $(\beta=.268, \mathrm{P}<.01)$ and personal familiarity $(\beta=.422, \mathrm{P}<.01)$ as user characteristics variables and social influence $(\beta=.089, \mathrm{P}$ $<.05)$ and social interaction $(\beta=.198, \mathrm{P}<.01)$ as social characteristics variables, and perceived ease of use $(\beta=.254, \mathrm{P}<.01)$ all have a significant positive effect on perceived availability. In addition, it is shown that perceived ease of use $(\beta=.240, \mathrm{P}<.01)$ and perceived availability ( $\beta$ $=.521, \mathrm{P}<.01)$ as intervening variables had a significant positive effect on the continuous intention to use.

Table 1. Study model analysis results

\begin{tabular}{|c|c|c|c|c|}
\hline Route & Coefficient & S.E. & C. R. & P \\
\hline personal innovativeness $\rightarrow$ perceived ease of use & .249 & .056 & $4.238^{* *}$ & .000 \\
\hline personal familiarity $\rightarrow$ perceived ease of use & .330 & .067 & $4.804^{* *}$ & .000 \\
\hline social influence $\rightarrow$ perceived ease of use & .137 & .053 & $2.218^{*}$ & .014 \\
\hline social interaction $\rightarrow$ perceived ease of use & .197 & .052 & $3.446^{* *}$ & .001 \\
\hline personal innovativeness $\rightarrow$ perceived availability & .268 & .045 & $5.386^{* *}$ & .000 \\
\hline personal familiarity $\rightarrow$ perceived availability & .422 & .052 & $7.546^{* *}$ & .000 \\
\hline social influence $\rightarrow$ perceived availability & .089 & .039 & $1.889^{*}$ & .030 \\
\hline social interaction $\rightarrow$ perceived availability & .198 & .040 & $4.309^{* *}$ & .000 \\
\hline perceived ease of use $\rightarrow$ perceived availability & .254 & .042 & $5.828^{* *}$ & .000 \\
\hline perceived ease of use $\rightarrow$ continuous intention to use & .240 & .049 & $4.770^{* *}$ & .000 \\
\hline perceived availability $\rightarrow$ continuous intention to use & .521 & .051 & $10.353^{*}$ & .000 \\
\hline
\end{tabular}

$* P<.05, * * P<.01$

\section{Discussion and results}

As a result of this study, user characteristics factors and social interaction have a positive influence on perceived availability and perceived ease of use as intervening variables. These results are consistent with the findings of previous studies and thus reaffirm that user and social characteristics factors are important ones to affect perceived availability and ease of use.

It is estimated that perceived availability and ease of use have a positive effect on the continuous use intention of enterprise mobile SNS. It is also shown that the extended technology acceptance model can be applied not only to the existing study object, online websites but also to the corporate mobile SNS users.

The results of this study provide important practical implications for communication and relationship formation between corporate mobile SNS and its users. First, as the mobile environment evolves into a user-driven SNS environment, it is necessary to strive to improve 
relationship formation by increasing the efficiency in a method to redefine convenient interface and management system from the user-centered viewpoint and by allowing users with high utilization of corporate mobile SNS to assume role and responsibility as a subject. Second, it will be necessary to strive to develop contents that can provide customized services for corporate mobile SNS, which increase the usability by inducing individuality and interest to stimulate the user's mind and attract the efficacy. Through these efforts, it will be possible to effectively develop and integrate the enterprise business model. Second, hard works will be required to stimulate the users' minds by causing individuality and interest through the development of content that can provide customized services of corporate mobile SNS and to enhance usability by attracting a sense of efficacy. In addition, the corporate mobile SNS can be made into a new corporate culture by reflecting users' voluntary opinions and experiences as a means of communication and forming a virtuous cycle structure of reproduction

\section{References}

[1] F. D. Davis, R. P. Bagozzi, and P. R. Warshaw, "Extrinsic and intrinsic motivation to use computers in the workplace,” Journal of Applied Social Psychology, vol.22, no.14, pp.1111-1132

[2] F. D. Davis, "Perceived usefulness, perceived ease of use, and user acceptance of information technology," MIS Quarterly, vol.13, no.3, pp.319-340

[3] M. S. Choi, "A study on the influence of factors such as personal innovativeness, social influence and user interface on smartphone acceptance: Based on an expanded technology acceptance model," Division of Media the Graduate School of Ewha Woman's University, (2011)

[4] V. Venkatesh and H. Bala, "Technology acceptance model 3 and a research agenda on interventions," Decision Sciences, vol.39, no.2, pp.273-315, (2008)

[5] V. Venkatesh and F. D. Davis, "A theoretical extension of the technology acceptance model: Four longitudinal field studies,” Management Science, vol.46, no.2, pp.186-204, (2000)

[6] R. Agarwal and E. Karahanna, "Time flies when you're having fun: cognitive absorption and beliefs about information technology usage,” MIS Quarterly, vol.24, no.4, pp.665-694, (2000)

[7] J. Kishoe, L. Patnaik, V. Mani, and V. Agrawal, "Genetic programming-based pattern classification with feature space partitioning," Information Sciences, vol.131, no.4, pp.65-86, (2001)

[8] H. Vekasalo, C. Lopez-Nicolas, F. J. Molina-Castillo, and H. Bouwman, "Analysis of users and non-users of smartphone applications," Telematics and Informatics, vol.27, no.3, pp.242-255, (2010)

[9] C. K. Keum and B. G. Kim, "A study on the influence of the enterprise mobile network service on continuous use intention,” Journal of Information Systems, spring, no.1, pp.906-912, (2014)

[10] J. H. Kim and K. S. Ha, "The study of the effects of the enterprise mobile network service on user satisfaction and the continuous use intention," Journal of Digital Convergence, vol.10, no.8, pp.135-148, (2012)

[11] F. Buelingen and M. Woerter, "Development perspectives, firm strategies, and applications in mobile commerce,” Journal of Business Research, vol.57, no.12, pp.1402-1408

[12] E. M. Rogers, "Diffusion of innovations 5th ed," Free Press, (2003)

[13] V. Venkatesh, M. G. Morris, G. B. Davis, and F. D. Davis, "User acceptance of information technology: Toward a unified view,” MIS Quarterly, vol.27, no.3, pp. 425-478, (2003)

[14] J. Y. L. Thong, S. J. Hong, and K. Y. Tam, "The effects of post-adoption beliefs on the expectation-confirmation model for information technology continuance," International Journal of Human-Computer Studies, vol.64, no.9, pp.799-810, (2006) 
The Effects of User and Social Characteristics on Continuous Use Intention among Corporate Mobile SNS Users - With a Focus on Extended Technological Acceptance Model

This page is empty by intention. 